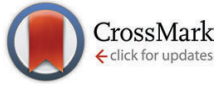

Cite this: J. Mater. Chem. C, 2015, 3, 9170

Received 14th June 2015 Accepted 31st July 2015

DOI: $10.1039 / \mathrm{c} 5 \mathrm{tc} 01754 \mathrm{~h}$

www.rsc.org/MaterialsC

\section{Twisted hexaazatrianthrylene: synthesis, optoelectronic properties and near-infrared electroluminescent heterojunctions thereof $\dagger$}

\author{
Diego Cortizo-Lacalle, ${ }^{a}$ Antonio Pertegás, ${ }^{b}$ Laura Martínez-Sarti, ${ }^{b}$ \\ Manuel Melle-Franco, ${ }^{c}$ Henk J. Bolink* ${ }^{* b}$ and Aurelio Mateo-Alonso*ad \\ The synthesis, optoelectronic properties and near-infrared electroluminescent heterojunctions of a \\ twisted and soluble 7,8,15,16,23,24-hexaazatrianthrylene derivative are reported.
}

\section{Introduction}

Near-infrared organic light-emitting diodes (NIR-OLEDs) ${ }^{1}$ are receiving a great deal of attention due to their potential applications in broad-band optical communications, night-vision technologies, and among others. In general, the emission in NIR-OLEDs originates from the radiative relaxation of excitons crossing the inherent low HOMO-LUMO gaps of NIR dyes and polymers. ${ }^{2}$ However, organic NIR-emitting materials are scarce because low HOMOLUMO gaps favour non-emissive deactivation pathways, ${ }^{3}$ and also, many of the low HOMO-LUMO gap organics possess limited photo- and chemical stability.

An alternative way to fabricate NIR-OLEDs without the use of NIR emitters consists of exploiting the exciplex-based emission that originates at organic heterojunctions ${ }^{4}$ between $p$-type and n-type materials. In this case, the emission is the result of the radiative decay of a charge pair exciton formed between the LUMO of the n-type material and the HOMO of the p-type material. Therefore, the emission of low energy photons can be achieved by a careful selection of stable organic semiconductors. For example, red $^{4 b}$ (670 nm) and NIR-emitting ${ }^{4 c, 5}(816 \mathrm{~nm})$ exciplexes have been obtained from green 5,6,11,12,17,18-hexaazatrinaphtylene (HATNA) emitters ( $\mathrm{S}_{6}$-HATNA and twisted-HATNA, respectively) - a family of electron-conducting N-containing starphenes - combined

\footnotetext{
${ }^{a}$ POLYMAT, University of the Basque Country UPV/EHU, Avenida de Tolosa 72, E-20018 Donostia-San Sebastian, Spain. E-mail: amateo@polymat.eu

${ }^{b}$ Instituto de Ciencia Molecular, Universidad de Valencia, c/Catedrático J. Beltrán 2, 46980 Paterna, Spain. E-mail: henk.bolink@uv.es

${ }^{c}$ Centro ALGORITMI, 4710-057 Braga, Portugal

${ }^{d}$ Ikerbasque, Basque Foundation for Science, Bilbao, Spain

$\dagger$ Electronic supplementary information (ESI) available. See DOI: 10.1039/ c5tc01754h
}
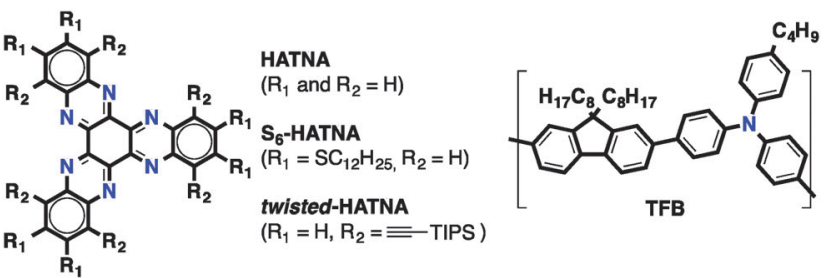

Fig. 1 Structure of HATNA and TFB.

with hole-conducting poly(9,9'-dioctylfluorene-alt- $N$-(4-butylphenyl)diphenylamine) (TFB) (Fig. 1).

In analogy to linear systems, ${ }^{2 a, 6}$ extending the conjugation of HATNA by condensing additional rings will provide materials with lower LUMO levels and thus, heterojunctions with deeper NIR luminescence. Yet, such extended starphenes are very insoluble ${ }^{7}$ and thus difficult to synthesise, purify and characterise because of their great tendency to aggregate through $\pi-\pi$ and van der Waals interactions. This lack of solubility also hampers the preparation of blends with other p-type materials and consequently processing thereof by means of low-cost and large-area liquid deposition methods.

In this work, we report the synthesis of twisted 7,8,15,16,23,24hexaazatrianthrylene (twisted-HATANT) (Scheme 1), an extended member of the N-containing starphene family. While, starphenes with an equal number of fused rings are virtually insoluble, ${ }^{7 a, b}$ twisted-HATANT shows a high solubility because of the distorted $\pi$-system and the six triisopropylsilyl (TIPS) substituents. The enhanced solubility of twisted-HATANT allows the preparation of blends with TFB and the deposition thereof by liquid methods. Furthermore, twisted-HATANT/TFB organic heterojunctions show NIR electroluminescence arising from the exciplex at substantially higher wavelengths $(848 \mathrm{~nm})$ than those previously reported ${ }^{4 b, 5}$ for HATNA heterojunctions. 

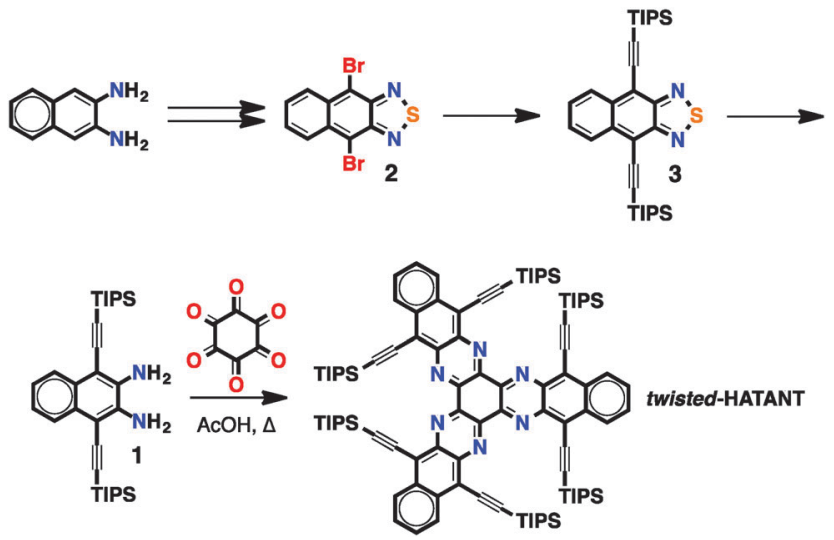

Scheme 1 Synthesis and structure of twisted-HATANT.

\section{Results and discussion}

\section{Synthesis and structure}

The synthesis of twisted-HATANT was achieved following the synthetic route set out in Scheme 1. Even if naphthalenediamine 1 has been previously reported, ${ }^{8}$ we have developed an alternative synthetic route. First, dibromothiadiazole 2 was prepared from the commercially available 1,2-naphthalenediamine in two steps following reported procedures. ${ }^{9}$ Then, $\mathbf{2}$ was transformed into acetylene-substituted thiodiazole 3 by Stille coupling. The reduction of the thiadiazole ring of 3 with $\mathrm{LiAlH}_{4}$ provided diamine $1 .^{8}$ Finally, twisted-HATANT was obtained by cyclocondensation of $\mathbf{1}$ with 1,2,3,4,5,6-hexaketonecyclohexane in refluxing acetic acid. The yield of twisted-HATANT is low (3\%) in comparison to the structurally equivalent twisted-HATNA ${ }^{5}$ $(32 \%)$. This low yield is consistent with the lower nucleophilicity of diamine $\mathbf{1}$, a recent report describes the formation of the linear diketon $\mathrm{e}^{10}$ as a side but major product, and the difficult purification, which reflect that both the synthesis and purification of twisted-HATANT are quite challenging.

DFT calculations using a B3LYP-6-31g(d,p) Hamiltonian ${ }^{11}$ reveal a propeller-like structure for twisted-HATANT (Fig. 2), consistent with the previously reported crystal structure ${ }^{5}$ of twisted-HATNA. Most importantly, the calculations evidence a higher average twist angle between blades of $67^{\circ}\left(65^{\circ}, 68^{\circ}\right.$ and $69^{\circ}$ for each blade) in comparison to the calculated twist angles of twisted-HATNA $\left(64^{\circ}\right)$ at the same level. The twist angle between blades is defined as the torsion angle between carbon A, B, C and D (Fig. 2). The higher level of distortion can be rationalised in terms of the more strained structure of HATANT due to the additional annulated ring.
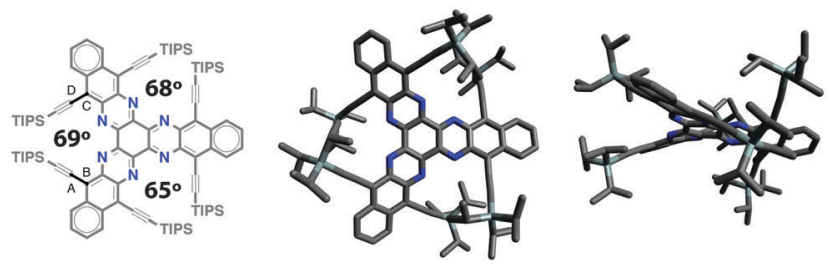

Fig. 2 DFT-calculated structure and twist angles of twisted-HATANT.

\section{Optical and electrochemical characterisation}

The colour of twisted-HATANT is old brick red with a red photoluminescence. The absorption features of twisted-HATANT in $\mathrm{CHCl}_{3}$ (maxima at 319, 331, 401, 556, and $597 \mathrm{~nm}$ ) correspond to those of previously reported ${ }^{5}$ for twisted-HATNA but as expected they appear to be substantially red-shifted, as much as $138 \mathrm{~nm}$ (Fig. 3 and Fig. S4, ESI $\dagger$ ). The photoluminescence spectrum of twisted-HATANT in $\mathrm{CHCl}_{3}$ obtained by excitation at $400 \mathrm{~nm}$ reveals a featureless band centred at $636 \mathrm{~nm}$ with a shoulder at $687 \mathrm{~nm}$ that extends into the NIR up to $820 \mathrm{~nm}$ (Fig. 3). The photoluminescence of twisted-HATANT is also substantially red-shifted $(132 \mathrm{~nm})$ in comparison to twistedHATNA $^{5}$ (Fig. S4, ESI $\dagger$ ).

To shed light on the nature of the electronic transitions of twisted-HATANT, the lower energy singlet excited states were calculated using the program Gaussian $09^{11}$ using timedependent density functional theory (TD-DFT B3LYP- $\mathrm{CHCl}_{3}-6$ $31 \mathrm{~g}(\mathrm{~d}, \mathrm{p}))$. From TD-DFT it is found that all excited states are singlets (transitions involving triplets were found to be optically inactive). The TD-DFT model computes the experimental band centred at $597 \mathrm{~nm}$ as a HOMO $\rightarrow$ LUMO transition at $715 \mathrm{~nm}$. The experimental band centred at 556 is calculated as the sum of two electronic transitions: HOMO-1 $\rightarrow$ LUMO and HOMO-2 $\rightarrow$ LUMO at $\sim 680 \mathrm{~nm}$. The experimental band at $401 \mathrm{~nm}$ is calculated as the sum of several transitions from HOMO -1 and HOMO -2 to LUMO+1 and LUMO+2 that range from 528 to $537 \mathrm{~nm}$. This arises from the fact that HOMO-1/HOMO-2 and LUMO+1/LUMO +2 couples are, respectively, nearly degenerated with $\Delta E<8 \mathrm{meV}$.

Cyclic voltammograms of twisted-HATANT $\left(0.1 \mathrm{M} n \mathrm{Bu}_{4} \mathrm{PF}_{6}\right.$ in $\mathrm{CH}_{2} \mathrm{Cl}_{2}$ ) exhibit two reduction waves at $E_{1 / 2}=-0.66$ and $-0.95 \mathrm{~V}$ (Fig. 4), which were assigned to the radical-anion and the dianion in analogy to phenazine derivatives. ${ }^{12}$ When the scans were performed close to the reduction of the solvent-supported electrolyte an additional irreversible curve was observed with peak potential $E_{\mathrm{pc}}=-1.64 \mathrm{~V}$ from which an additional process evolved with peak potential $E_{\mathrm{pa}}=-1.16 \mathrm{~V}$ on the reverse scan. On the oxidative scan, no redox processes were observed within the solvent-supported electrolyte window.

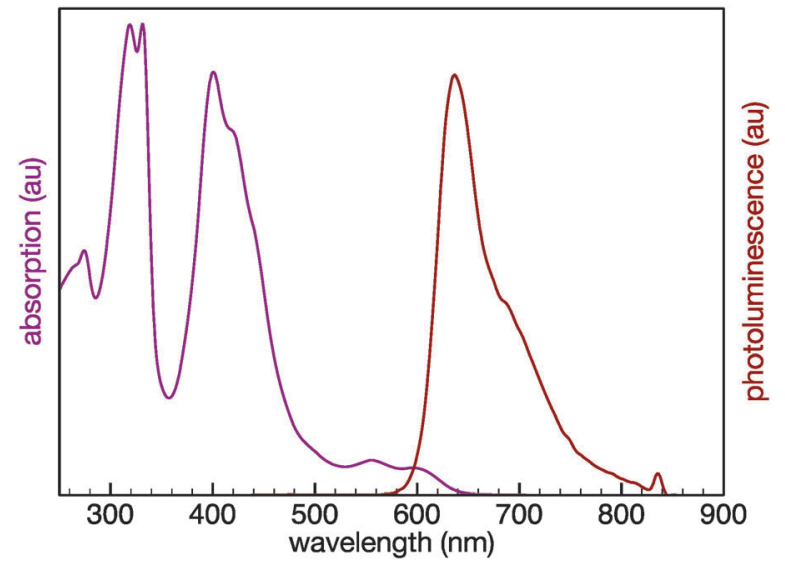

Fig. 3 Absorption and photoluminescence spectra of twisted-HATANT. 


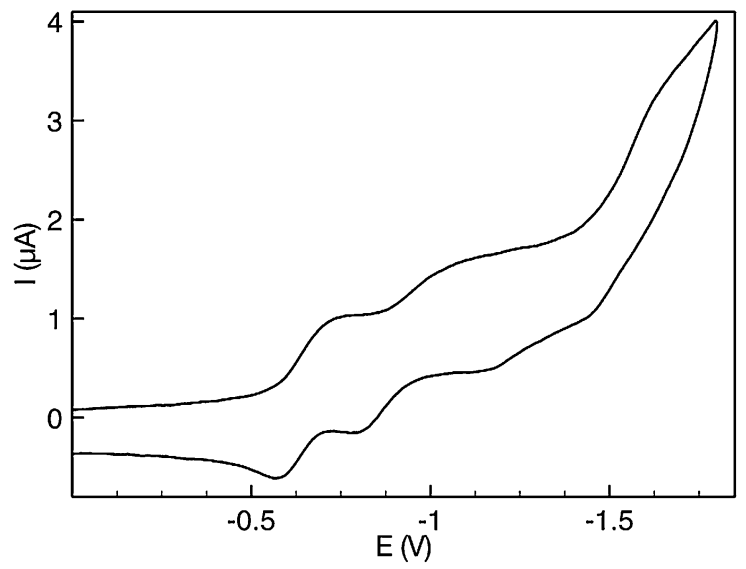

Fig. 4 Cyclic voltammogram of twisted-HATANT.
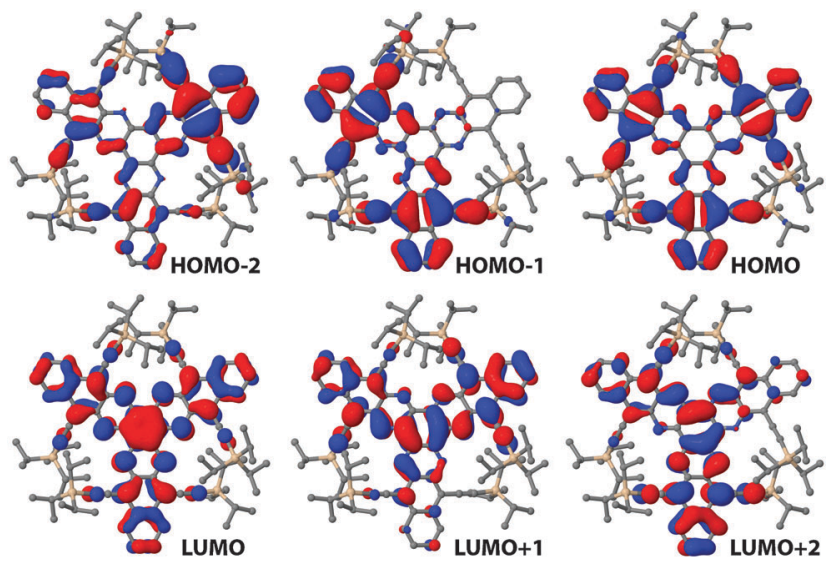

Fig. 5 Molecular orbitals of twisted-HATANT.

\section{Energy levels}

The HOMO-LUMO gap of twisted-HATANT (1.9 eV) was estimated from the absorption onset. The electrochemical LUMO of twistedHATANT $(-3.8 \mathrm{eV})$ was estimated from the potential onsets of the first reduction waves. The theoretical estimation, $\mathrm{B} 3 \mathrm{LYP}_{\mathrm{CHCL}}-\mathrm{CH}_{3}-$ $31 \mathrm{~g}(\mathrm{~d}, \mathrm{p})$, of the HOMO-LUMO gap (2.1 eV) and the LUMO $(-3.4 \mathrm{eV})$ are in good agreement with the HOMO-LUMO gap and the LUMO estimated experimentally. In the simulations, both HOMO and LUMO are delocalised along the HATANT core. Nevertheless the HOMO coefficients are larger in the points (the naphthyl residue) of twisted-HATANT, while larger coefficients are found in the central ring for the LUMO (Fig. 5).

\section{Electroluminescence}

OLEDs incorporating a blend of twisted-HATANT:TFB (1:1) were fabricated with the device structure shown in Fig. 6. On an ITO electrode, a PEDOT:PSS layer $(70 \mathrm{~nm})$ followed by a twistedHATANT:TFB layer (95 nm) were deposited via spin coating. On top of which, a Ba cathode $(5 \mathrm{~nm})$ and a silver contact $(70 \mathrm{~nm})$ were evaporated, consecutively. The electroluminescence spectrum and the current and radiance versus voltage characteristics of the OLEDs were recorded and are shown in Fig. 7 and 8.

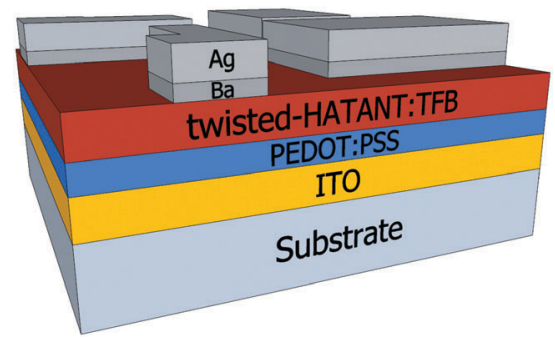

Fig. 6 Device architecture.

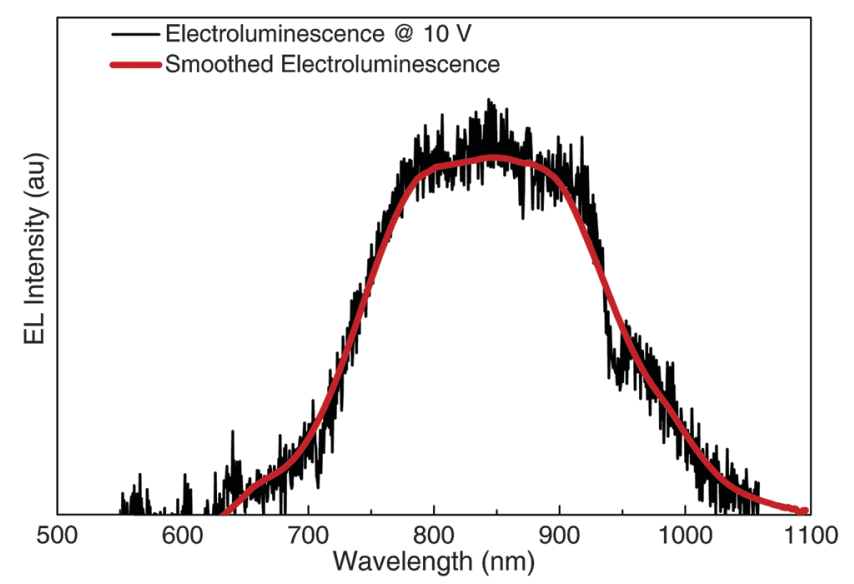

Fig. 7 Electroluminescence spectrum of twisted-HATANT:TFB.

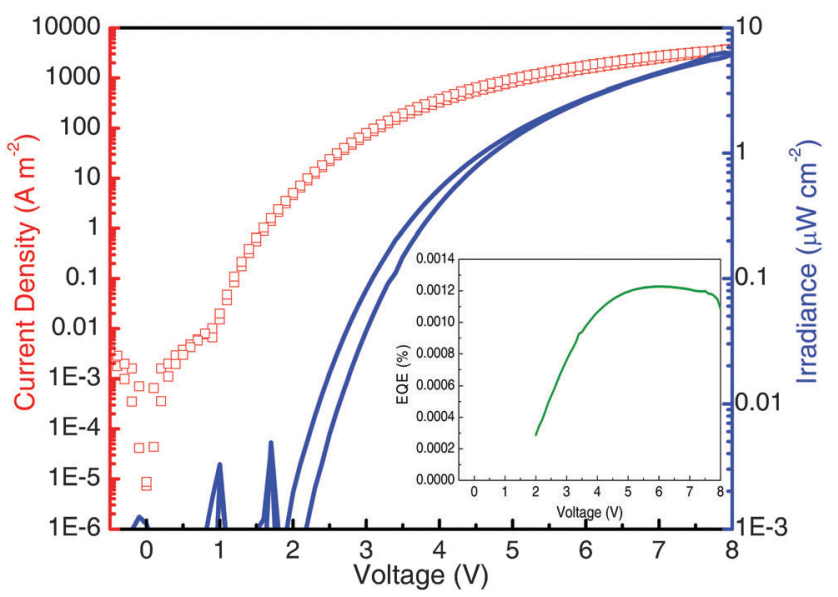

Fig. 8 Current and irradiance versus voltage characteristics of twistedHATANT:TFB.

The electroluminescence spectrum displays a structureless emission band centred at $848 \mathrm{~nm}(1.46 \mathrm{eV})$. This is consistent with the emission of an exciplex state estimated at $1.5 \mathrm{eV}$ from the individual HOMO of $\mathrm{TFB}^{4 c}$ and LUMO of twisted-HATANT. Importantly, no emission from twisted-HATANT or TFB was detected. The LEDs show a turn on voltage of about $2 \mathrm{~V}$ and an irradiance of $6.3 \mu \mathrm{W} \mathrm{cm} \mathrm{cm}^{-2}$ at a current density of $100 \mathrm{~A} \mathrm{~m}^{-2}$ with an external quantum efficiency (EQE) of $0.0012 \%$ (inset Fig. 8). Although these values seem to be low, they are within 
the expectations ${ }^{13}$ for LEDs with emission at similar and lower energies and in agreement with the energy gap law. ${ }^{3}$

\section{Experimental}

\section{Synthetic procedures}

Reagents for synthesis were, if not otherwise specified, purchased from Aldrich, Fluka or Acros. Commercial chemicals and solvents were used as received. Anhydrous chloroform from Sigma-Aldrich was used as purchased. Anhydrous THF was dried using an Innovative Pure Solve solvent purification system. Column chromatography was carried out using Silica gel $60(40-60 \mu \mathrm{m})$ from Scharlab. Analytical thin layer chromatography (TLC) was carried out using aluminum sheets $(20 \times 20 \mathrm{~cm})$ pre-coated with silica gel RP-18W 60 F254 from Merck. UV-active compounds were detected using a UV-lamp from CAMAG at wavelength $\lambda=254$ or $366 \mathrm{~nm}$. NMR spectra were recorded on a Bruker Avance 400 spectrometer at $298 \mathrm{~K}$ using partially deuterated solvents as internal standards. Matrix Assisted Laser Desorption Ionization (coupled to a Time-OfFlight analyzer) experiments (MALDI-TOF) were recorded on a Bruker REF LEX spectrometer in POLYMAT by Dr Antonio Veloso. Absorption and emission spectra were recorded on a Perkin-Elmer Lambda 950 spectrometer and a LS55 Perkin-Elmer Fluorescence spectrometer, respectively. Electrochemical measurements were carried out on a Princeton Applied Research Parstat 2273 in a 3-electrode single compartment cell with a Pt disc working electrode ( $\varnothing=0.5 \mathrm{~mm}$ ), a platinum wire counter electrode $(\varnothing=0.5 \mathrm{~mm})$ and a silver wire pseudoreference electrode. The cell and the electrodes were custom made. The reduction potentials were referred to SCE using ferrocene $(\mathrm{Fc})$ as internal reference $\left(E_{1 / 2}^{\mathrm{Fc}(\mathrm{SCE})}=+0.48 \mathrm{~V}\right)$ after the measurements.

Compound 3. Compound $2^{9}(150 \mathrm{mg}, 0.43 \mathrm{mmol}, 1.0$ eq.) and $\mathrm{Pd}\left(\mathrm{PPh}_{3}\right)_{2} \mathrm{Cl}_{2}(45 \mathrm{mg}, 0.06 \mathrm{mmol})$ are dissolved in dry toluene $(10 \mathrm{~mL})$ and then TIPS ((tributylstannyl)ethynyl)silane (616 mg, $1.31 \mathrm{mmol}, 3$ eq.) is added. The reaction is stirred at $110{ }^{\circ} \mathrm{C}$ for $48 \mathrm{~h}$ under nitrogen. $\mathrm{CH}_{2} \mathrm{Cl}_{2}$ was added to the reaction mixture and washed with water $(50 \mathrm{~mL})$, brine $(50 \mathrm{~mL})$ and water $(50 \mathrm{~mL})$. The organic layer was dried over $\mathrm{MgSO}_{4}$, filtered and the solvents evaporated. Column chromatography on silica (eluent mixture, hexane/ $\mathrm{CH}_{2} \mathrm{Cl}_{2}, 4: 1$ ) was carried out. The main fractions were precipitated, the precipitate was filtered and a bright pink solid was obtained (104 mg, 48\%). ${ }^{1} \mathrm{H}$ NMR $\left(\mathrm{CDCl}_{3}\right)$ : 8.60-8.54 (q, 2H), 7.61-7.53 (q, 2H) and 1.32-1.23 (m, 42H). ${ }^{1} \mathrm{H}-\mathrm{NMR}$ is consistent with previous reports. ${ }^{8 a}$

twisted-HATANT. Compound $3(100 \mathrm{mg}, 0.18 \mathrm{mmol})$ is dissolved in dry THF under nitrogen and the solution is cooled down to $0{ }^{\circ} \mathrm{C}$. Lithium aluminium hydride $(60 \mathrm{mg}, 1.57 \mathrm{mmol}$, 8.6 eq.) is added portionwise and the reaction is stirred overnight at room temperature. Ammonium chloride (aq.) is slowly added and the product is extracted with $\mathrm{CH}_{2} \mathrm{Cl}_{2}$. The organic phase is dried over sodium sulfate and evaporated yielding compound 1. ${ }^{1} \mathrm{H}-\mathrm{NMR}$ of compound $\mathbf{1}$ is consistent with previous reports. $^{8 b}$ Compound 1 (3.1 eq.) and 1,2,3,4,5,6-hexaketocyclohexane octahydrate $(20 \mathrm{mg}, 62 \mu \mathrm{mol}, 1.0$ eq.) are suspended in acetic acid $(5 \mathrm{~mL})$ and the mixture is bubbled with nitrogen for
20 minutes. The reaction is refluxed for $48 \mathrm{~h}$ under nitrogen. The mixture is dissolved in $\mathrm{CH}_{2} \mathrm{Cl}_{2}$ and washed with water $(3 \times 25 \mathrm{~mL})$. The organic phase is dried over sodium sulfate and evaporated. Column chromatography on silica (eluent mixture, hexane $/ \mathrm{CH}_{2} \mathrm{Cl}_{2}$, $8: 1)$ was carried out. The product was isolated as dark powder (10 mg, 3\%). ${ }^{1} \mathrm{H}$ NMR $\left(\mathrm{CDCl}_{3}\right): 8.86-8.79(\mathrm{q}, 6 \mathrm{H}), 7.80-7.73$ (q, 6H) and 1.23-1.18 (m, 126H); ${ }^{13} \mathrm{C} \mathrm{NMR}\left(\mathrm{CDCl}_{3}\right): 143.62,140.90,135.74$, 128.56, 127.94, 122.97, 109.57, 102.64, 19.13 and 11.88; EM (MALDI-TOF) $(\mathrm{m} / \mathrm{z})$ : calculated for $\mathrm{C}_{102} \mathrm{H}_{138} \mathrm{~N}_{6} \mathrm{Si}_{6}$ : 1615.96 ; found: $1616.99[\mathrm{M}+\mathrm{H}]^{+}$and $1638.98[\mathrm{M}+\mathrm{Na}]^{+}$; UV-vis $(\log \varepsilon): 401$ (5.06), 419 (4.96), 556 (3.95), 597 (3.88).

\section{OLED fabrication}

The sandwiched OLEDs were prepared as follows: the pre-patterned ITO glass plates were extensively cleaned, using water-soap, water and 2-propanol baths and UV-ozone treatment, just before the deposition of the thin films. Prior to the deposition of the active layer, an $80 \mathrm{~nm}$ layer of poly(3,4-ethylenedioxythiophene) polystyrene sulfonate (PEDOT:PSS, CLEVIOS ${ }^{\mathrm{TM}}$ P VP AI 4083, aqueous dispersion, $1.3-1.7 \%$ solid content, Heraeus) was deposited. Subsequently, the twisted-HATANT:TFB blend was deposited by spin-coating using $10 \mathrm{mg} \mathrm{mL}^{-1}$ (1:1 mass ratio) of chlorobenzene solution, which yields a $90 \mathrm{~nm}$ thick layer. The film thickness was determined using an Ambios XP1 profilometer. After spinning the organic layers, the samples were transferred to an inert atmosphere glovebox $\left(<0.1 \mathrm{ppm} \mathrm{O}_{2}\right.$ and $\mathrm{H}_{2} \mathrm{O}$, MBraun). Barium (5 nm) and silver $(70 \mathrm{~nm})$ were thermally evaporated using a shadow mask under a vacuum $\left(<1 \times 10^{-6} \mathrm{mbar}, 1\right.$ bar $\left.\approx 100000 \mathrm{~Pa}\right)$ using an Edwards Auto500 evaporator integrated into an inert atmosphere glovebox. $I-V-L$ measurements were obtained by applying a voltage scan over the device and monitoring the current flow (using a Keithley 2400 sourcemeter) and simultaneously the current generated by a Si-photodiode (Hamamatsu S1336-8BK) using a Keithley 6485 picoamperometer calibrated using a Minolta LS100 luminance meter. The electroluminescence spectra were recorded using an Avantes AvaSpec-2048 Fiber Optic Spectrometer.

\section{Conclusions}

We have reported the synthesis and characterisation of twistedHATANT, an extended and distorted member of the N-containing starphene family. In contrast to starphenes with an equal number of rings ${ }^{7 a, b}$ twisted-HATANT is highly soluble in organic solvents, which allowed a complete characterisation (including absorption, emission, and cyclic voltammetry) and the estimation of its electronic properties. Calculations carried out at the DFT level illustrate the distorted nature of twisted-HATANT and also provide a detailed perspective on the nature of the observed optoelectronic properties. Furthermore, the enhanced solubility of twisted-HATANT allowed the preparation of blends with TFB and the deposition thereof by spin coating. OLEDs fabricated from such blends show NIR electroluminescence that originates from the exciplex at the twistedHATANT/TFB heterojunction. The electroluminescence appears at substantially higher wavelengths (centred at $848 \mathrm{~nm}$ ) than for previously reported ${ }^{4 b, 5}$ heterojunctions with HATNA derivatives 
and is consistent with the extended conjugation of the HATANT core. Overall this work illustrates that electron-deficient $\mathrm{N}$-containing starphenes can be considered a general platform to prepare and fine-tune the properties of exciplex-based NIR-OLEDs.

\section{Acknowledgements}

We are grateful to the Basque Science Foundation for Science (Ikerbasque), POLYMAT, the University of the Basque Country (SGIker), Deutsche Forschungsgemeinschaft (AU 373/3-1 and MA 5215/4-1), Gobierno de España (Ministerio de Economía y Competitividad, MAT2012-35826 and MAT2014-55200), Gobierno Vasco (BERC program), Diputación Foral de Guipuzcoa, the Fundação para a Ciência e a Tecnologia, ON2 (NORTE07-0162-FEDER-000086), the Generalitat Valenciana (Prometeo/ 2012/053) and the European Union (ERA-Chemistry, Career Integration Grant No. 618247, and FEDER).

\section{Notes and references}

1 Z. I. Wang, Near-Infrared Organic Materials and Emerging Applications, CRC Press, 2013.

2 (a) R. Garcia, M. Melle-Franco and A. Mateo-Alonso, Chem. Commun., 2015, 51, 8037-8040; (b) L. Yao, S. Zhang, R. Wang, W. Li, F. Shen, B. Yang and Y. Ma, Angew. Chem., Int. Ed., 2014, 53, 2119-2123; (c) B. Stender, S. F. Völker, C. Lambert and J. Pflaum, Adv. Mater., 2013, 25, 2943-2947; (d) M. Chen, E. Perzon, M. R. Andersson, S. Marcinkevicius, S. K. M. Jönsson, M. Fahlman and M. Berggren, Appl. Phys. Lett., 2004, 84, 3570-3572.

3 R. Englman and J. Jortner, Mol. Phys., 1970, 18, 145-164.

4 (a) Y.-s. Huang, S. Westenhoff, I. Avilov, P. Sreearunothai, J. M. Hodgkiss, C. Deleener, R. H. Friend and D. Beljonne, Nat. Mater., 2008, 7, 483-489; (b) J. Clark, R. Archer, T. Redding, C. Foden, J. Tant, Y. Geerts, R. H. Friend and C. Silva, J. Appl. Phys., 2008, 103, 124510; (c) G. Tregnago, C. Fléchon, S. Choudhary, C. Gozalvez, A. Mateo-Alonso and F. Cacialli, Appl. Phys. Lett., 2014, 105, 143304; (d) T.-W. Ng, M.-F. Lo, M.-K. Fung, W.-J. Zhang and C.-S. Lee, Adv. Mater., 2014, 26, 5569-5574.

5 S. Choudhary, C. Gozalvez, A. Higelin, I. Krossing, M. MelleFranco and A. Mateo-Alonso, Chem. - Eur. J., 2014, 20, 1525-1528.

6 (a) A. Mateo-Alonso, C. Ehli, K. H. Chen, D. M. Guldi and M. Prato, J. Phys. Chem. A, 2007, 111, 12669-12673; (b) A. Mateo-Alonso, N. Kulisic, G. Valenti, M. Marcaccio, F. Paolucci and M. Prato, Chem. - Asian J., 2010, 5, 482-485; (c) N. Kulisic, S. More and A. Mateo-Alonso, Chem. Commun., 2011, 47, 514-516; (d) S. More, R. Bhosale, S. Choudhary and A. Mateo-Alonso, Org. Lett., 2012, 14, 4170-4173; (e) R. García, S. More, M. Melle-Franco and A. Mateo-Alonso, Org. Lett., 2014, 16, 6096-6099; $(f)$ A. Mateo-Alonso, Chem. Soc. Rev., 2014, 43, 6311-6324; $(g)$ P. Bodis, M. R. Panman, B. H. Bakker, A. Mateo-Alonso, M. Prato, W. J. Buma, A. M. Brouwer,
E. R. Kay, D. A. Leigh and S. Woutersen, Acc. Chem. Res., 2009, 42, 1462-1469; (h) S. More, R. Bhosale and A. Mateo-Alonso, Chem. - Eur. J., 2014, 20, 10626-10631; ( $i$ ) S. More, S. Choudhary, A. Higelin, I. Krossing, M. Melle-Franco and A. Mateo-Alonso, Chem. Commun., 2014, 50, 1976-1979; (j) A. B. Marco, D. Cortizo-Lacalle, C. Gozalvez, M. Olano, A. Atxabal, X. Sun, M. Melle-Franco, L. E. Hueso and A. MateoAlonso, Chem. Commun., 2015, 51, 10754-10757; (k) M. Grzelczak, N. Kulisic, M. Prato and A. Mateo-Alonso, Chem. Commun., 2010, 46, 9122-9124; (l) M. Grzelczak, N. Kulisic, M. Prato and A. Mateo-Alonso, Part. Part. Syst. Charact., 2014, 31, 121-125.

7 (a) E. Clar and A. Mullen, Tetrahedron, 1968, 24, 6719-6724; (b) S. R. Marder, B. Kaafarani, S. Barlow, B. Kippelen, B. Domercq, Q. Zhang and T. Kondo, Charge-transport materials, methods of fabrication thereof, and methods of use thereof, WO Pat., 2005/123737 A2, 2005; (c) E. Clar, The Aromatic Sextet, Wiley, London, 1972.

8 (a) A. L. Appleton, S. Miao, S. M. Brombosz, N. J. Berger, S. Barlow, S. R. Marder, B. M. Lawrence, K. I. Hardcastle and U. H. F. Bunz, Org. Lett., 2009, 11, 5222-5225; (b) S. Miao, S. M. Brombosz, P. v. R. Schleyer, J. I. Wu, S. Barlow, S. R. Marder, K. I. Hardcastle and U. H. F. Bunz, J. Am. Chem. Soc., 2008, 130, 7339-7344.

9 P. Wei, L. Duan, D. Zhang, J. Qiao, L. Wang, R. Wang, G. Dong and Y. Qiu, J. Mater. Chem., 2008, 18, 806-818.

10 C. Wang, J. Zhang, G. Long, N. Aratani, H. Yamada, Y. Zhao and Q. Zhang, Angew. Chem., Int. Ed., 2015, 54, 6292-6296.

11 M. J. Frisch, G. W. Trucks, H. B. Schlegel, G. E. Scuseria, M. A. Robb, J. R. Cheeseman, G. Scalmani, V. Barone, B. Mennucci, G. A. Petersson, H. Nakatsuji, M. Caricato, X. Li, H. P. Hratchian, A. F. Izmaylov, J. Bloino, G. Zheng, J. L. Sonnenberg, M. Hada, M. Ehara, K. Toyota, R. Fukuda, J. Hasegawa, M. Ishida, T. Nakajima, Y. Honda, O. Kitao, H. Nakai, T. Vreven, J. A. Montgomery Jr, J. E. Peralta, F. Ogliaro, M. J. Bearpark, J. Heyd, E. N. Brothers, K. N. Kudin, V. N. Staroverov, R. Kobayashi, J. Normand, K. Raghavachari, A. P. Rendell, J. C. Burant, S. S. Iyengar, J. Tomasi, M. Cossi, N. Rega, N. J. Millam, M. Klene, J. E. Knox, J. B. Cross, V. Bakken, C. Adamo, J. Jaramillo, R. Gomperts, R. E. Stratmann, O. Yazyev, A. J. Austin, R. Cammi, C. Pomelli, J. W. Ochterski, R. L. Martin, K. Morokuma, V. G. Zakrzewski, G. A. Voth, P. Salvador, J. J. Dannenberg, S. Dapprich, A. D. Daniels, Ö. Farkas, J. B. Foresman, J. V. Ortiz, J. Cioslowski and D. J. Fox, Gaussian 09, Gaussian, Inc., Wallingford, CT, USA, 2009.

12 (a) A. M. Alonso, R. Horcajada, H. J. Groombridge, R. Mandalia, M. Motevalli, J. H. P. Utley and P. B. Wyatt, Chem. Commun., 2004, 412-413; (b) A. M. Alonso, R. Horcajada, H. J. Groombridge, R. Chudasama, M. Motevalli, J. H. P. Utley and P. B. Wyatt, Org. Biomol. Chem., 2005, 3, 2832-2841; (c) A. M. Alonso, R. Horcajada, M. Motevalli, J. H. P. Utley and P. B. Wyatt, Org. Biomol. Chem., 2005, 3, 2842-2847.

13 (a) M. Sun, X. Jiang, W. Liu, T. Zhu, F. Huang and Y. Cao, Synth. Met., 2012, 162, 1406-1410; (b) G. Qian, Z. Zhong, M. Luo, D. Yu, Z. Zhang, Z. Y. Wang and D. Ma, Adv. Mater., 2009, 21, 111-116. 